\title{
BENEFÍCIOS DA ATIVIDADE FÍSICA E DO EXERCÍCIO FÍSICO NA DEPRESSÃO*
}

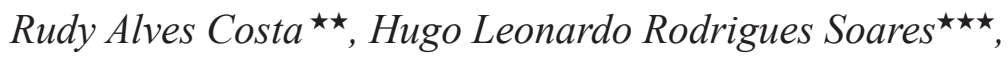 \\ José Antônio Caldas Teixeira ${ }^{\star \star \star \star}$
}

\author{
Palavras-chave: Depressão. Medicina do Exercício e do Esporte. Psicologia do \\ Esporte.
}

INTRODUÇÃO: Segundo as estimativas, utilizando a metodologia da Carga Global da Doença, proposta pela Organização Mundial de Saúde, para o ano de 2020, a doença isquêmica do coração e a depressão serão as duas maiores causas não só de mortalidade mas, de incapacidade sobre a população em geral. A depressão é caracterizada por tristeza, baixa da auto-estima, pessimismo, pensamentos negativos recorrentes, desesperança e desespero. Seus sintomas são, fadiga, irritabilidade, retraimento e ideação suicida. O humor depressivo pode aparecer como uma resposta a situações reais, por meio de uma reação vivencial depressiva, quando diante de fatos desagradáveis, aborrecedores, frustrações e perdas.Trata-se, neste caso, de uma resposta a conflitos íntimos e determinados por fatores vivenciais. A depressão está associada a uma alta incapacidade e perda social. Muitos estudos apontam à possibilidade de pessoas fisicamente ativas, em qualquer idade, apresentarem uma melhor saúde mental do que sedentários. Entre as hipoteses que tentam explicar a ação dos exercícios sobre a ansiedade e depressão, uma das mais aceita é a hipótese das Endorfinas. A teoria da endorfina sugere que a atividade física desencadearia uma secreção de endorfinas capaz de provocar um estado de euforia natural, por isso, aliviando os sintomas da depressão. Essa idéia, entretanto, não tem consenso entre os pesquisadores. Alguns deles, por exemplo, preferem acreditar que o exercício físico regularia a neurotransmissão da noradrenalina e da serotonina, igualmente aliviando os sintomas da depressão. Outra hipótese seria a cognitiva. De natureza eminentemente psicológica, a hipótese cognitiva se fundamenta na melhoria da autoestima mediante a prática do exercício, sustentando que os exercícios em longos prazos ou os exercícios intensivos melhorariam a imagem de si mesmo e, conseqüentemente, a autoestima.

* Trabalho apresentado na $28^{\mathrm{a}}$ Semana Científica da Faculdade de Medicina da UFF, de 29 de novembro a 02 de dezembro de 2005, na Associação Médica Fluminense, Niterói, Rio de Janeiro.

$\star \star$ Interno da Faculdade de Medicina da UFF.

$\star \star \star$ Membro da Sociedade de Medicina do Esporte do Rio de Janeiro e da Sociedade Brasileira de Medicina do Esporte.

E-mail: hlsoares@brfree.com.br

$\star \star \star \star \star$ Professor de Medicina do Exercício e do Esporte e Semiologia do Departamento de Medicina Clínica da Faculdade de Medicina da Universidade Federal Fluminense. Mestre em Cardiologia pela UFF e em Educação Física pela UFRJ. Vice-presidente da Sociedade de Medicina do Esporte do Rio de Janeiro. Membro da Câmara Técnica de Medicina Deportiva do Conselho Regional de Medicina do Rio de Janeiro. Orientador do trabalho.

E-mail: jacaldas@uninet.com.br 
OBJETIVO: Discutir a importância da prática regular de exercícios físicos como medida de prevenção e como adjuvante do tratamento da depressão, sendo o exercício físico uma importante abordagem não farmacológica que contribui para o desenvolvimento da auto-estima e da confiança do indivíduo.

METODOLOGIA: Elaboração de um levantamento bibliográfico baseado na pesquisa de artigos, livros e no acervo eletrônico de revistas da Internet.

RESULTADOS E CONCLUSÕES: A condição física se encontra positivamente ligada à saúde mental e ao bem estar; as depressões dos tipos moderadagrave ou grave e severa podem exigir um tratamento profissional que pode incluir a prescrição de medicamentos, a eletroconvulsoterapia ou a psicoterapia, nesses casos a atividade física serviria de complemento; no plano clínico, é opinião atual que a atividade física produz efeitos emotivos benéficos em quaisquer idades e sexos; as pessoas com um bom estado físico que necessitam um medicamento psicotrópico podem praticar com total segurança uma atividade física sob vigilância médica. $O$ tratamento padrão para depressão - psicoterapia e prescrição medicamentosa - é extremamente efetivo, porém a prática de atividade física é uma terapia adjuvante altamente benéfica. As pesquisas demonstram que a prática de exercícios regulares, além dos benefícios fisiológicos, acarreta benefícios psicológicos, tais como: melhor sensação de bem estar, humor e auto-estima, assim como, redução da ansiedade, tensão e depressão. 